\title{
Introduction of Potentially Allergenic Foods in the Infant's Diet during the First Year of Life in Five European Countries
}

\author{
Sonia A. Schiess ${ }^{a}$ Veit Grote ${ }^{b}$ Silvia Scaglioni ${ }^{c}$ Veronica Luque ${ }^{d}$ \\ Francoise Martin ${ }^{\mathrm{e}}$ Anna Stolarczyk ${ }^{f}$ Fiammetta Vecchic \\ Berthold Koletzko $^{a}$ for the European Childhood Obesity Project \\ a Division of Metabolic Diseases and Nutrition, Dr. von Hauner Children's Hospital, and ${ }^{b}$ Department of \\ Epidemiology, Institute of Social Pediatrics and Adolescent Medicine, Ludwig-Maximilian University, Munich,

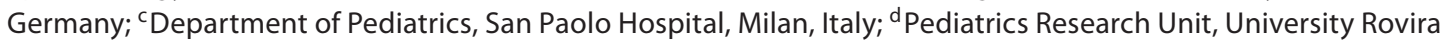 \\ i Virgili, Reus, Spain; ${ }^{~} \mathrm{CHC}$ St. Vincent, Liège, Belgium; ${ }^{\mathrm{f} C l i n i c}$ of Pediatrics, Children's Memorial Health Institute, \\ Warsaw, Poland
}

\section{Key Words}

Allergenic foods $\cdot$ Infant $\cdot$ Milk $\cdot$ Gluten $\cdot$ Fish $\cdot$ Egg

\begin{abstract}
Background: Little information is available on infants' age at first introduction of potentially allergenic foods as part of complementary feeding. We aimed to analyze age at the introduction of potentially allergenic foods in healthy term infants relative to recommendations in 5 European countries. Method: Recruitment was conducted from October 2002 to June 2004. A total of 1,678 infants [588 breastfed (BF) and 1,090 formula-fed (FF) infants] were studied. In 1,368 infants, at least one 3-day weighed food diary at the age of 1-9 and 12 completed months was available. Results: Six percent of BF infants and $13 \%$ of FF infants consumed some potentially allergenic food already prior to the recommended minimum age of 4 months, and $4 \%$ of BF infants and $11 \%$ of FF infants had already received gluten. There were significant differences in the timing of the introduction of potentially allergenic foods between the countries at the age of 4- 6 months $(p<0.001)$. Conclusion: The time of first introduction of po-
\end{abstract}

tentially allergenic foods in infants differed significantly between countries, and they were introduced much earlier than recommended in some countries. FF infants received potentially allergenic foods earlier than BF infants. Better information and counseling of parents is desirable.

Copyright $\odot 2011$ S. Karger AG, Basel

\section{Introduction}

Allergic manifestations in children have increased in both Western and developing countries [1]. Diet in infancy may have an effect on health throughout childhood and adulthood, including the manifestation of atopic diseases [1-6].

In 2001, the World Health Organization issued a revised global recommendation that infants should be exclusively breastfed during the first 6 months of life before any complementary food is introduced [7]. There were no specific guidelines for the introduction of complementary foods known as potentially allergenic foods, neither for healthy infants nor for infants with a risk of atopic

\section{KARGER}

Fax +41613061234 E-Mail karger@karger.ch www.karger.com
Prof. Berthold Koletzko, MD

Division of Metabolic and Nutritional Medicine

Dr. von Hauner Children's Hospital, University of Munich Medical Centre

Lindwurmstrasse 4, DE-80337 Munich (Germany)

Tel. +49 895160 2826, E-Mail office.koletzko@med.uni-muenchen.de 
diseases. Complementary foods like cow's milk, cereal with gluten, hen's egg, fish, nuts or soybean are considered potentially allergenic foods $[8,9]$.

Different studies have associated a very early introduction of complementary foods with an increased development of atopic diseases. Saarinen and Kajosaari [10] reported that breastfeeding for at least 6 months protected against atopic dermatitis throughout childhood and adolescence. Even though numerous observational studies have explored the potential impact of breastfeeding on the development of allergies and eczema, the data remain controversial [6]. The most convincing data are available for benefits of breastfeeding in infants at high risk with a first-degree relative with atopic disease, in which two meta-analyses found a transient protective effect of exclusive breastfeeding for at least 4 months on later atopic dermatitis, wheezing and asthma in infancy and early childhood $[11,12]$.

In Australian infants, the introduction of milk other than breast milk before 4 months of age had a strong association with asthma and atopy in children at the age of 6 years [13]. Infants exposed to 4 or more different types of solid foods before the age of 4 months had a 2.9 -fold higher risk of eczema up to the age of 10 years than those not exposed to early solid feeding [4]. Fiocchi et al. [14] suggested introducing complementary feeding after the age of 6 months with caution and only one kind at a time, including potentially allergenic foods like egg, peanut, nuts and fish. A review of the European Academy of Allergology and Clinical Immunology concluded that the most effective dietary measure for the prevention of atopic diseases even in high-risk patients is exclusive breastfeeding until preferably 6 months, but at least for 4 completed months with avoidance of solid foods and cows' milk in that time period $[9,15]$. However, recent studies showed delayed introduction of complementary foods associated with increased development of atopic disease [1, 16-21]. The ESPGHAN Committee on Nutrition recently concluded that there is no convincing scientific evidence that avoidance, or delayed introduction after the beginning of the 7th month of age, of potentially allergenic foods, such as fish and eggs, reduces allergies [5].

Here, we describe the practice of introducing potentially allergenic foods as part of complementary feeding in apparently healthy term infants in 5 European countries participating in the European Childhood Obesity Project, including countries of Central, Western, Eastern and Southern (Mediterranean) Europe with different traditions and eating behaviors.

\section{Subjects and Methods}

\section{Study Design}

It was our aim to analyze the consumption of potentially allergenic foods as part of complementary feeding versus recommendations in apparently healthy infants. Data were collected as part of the EU Childhood Obesity Project $[22,23]$. In brief, recruitment of healthy infants born at term occurred between 1 October 2002 and 31 July 2004 in 11 study centers in Germany (Munich and Nuremberg), Belgium (Brussels and Liège), Italy (Milan), Spain (Tarragona and Reus) and Poland (Warsaw).

Invited for the study were healthy, singleton, term infants with mothers $\geq 18$ years, with good knowledge of the national language and residence in the area of the respective study center. Exclusion criteria were mothers with hormonal or metabolic diseases or illicit addiction during pregnancy [22]. Mothers were approached by study personnel at the maternity hospitals before their discharge or via pediatricians and midwifes. After oral information and written consent, mothers and infants were invited for an initial medical visit with collection of anthropometric measurements and sociodemographic data as well as of data about the medical history of infants and parents including a history of allergy and atopic diseases, pregnancy and delivery. In the following months, parents and infants were followed up regularly with visits in the study centers and mailed questionnaires, including 3-day weighed food diaries at the age of 1-9 and 12 months.

\section{Study Population}

The study group comprised 2 double-blind randomized groups of infants fed formulae with different protein levels and 1 reference group of breastfed (BF) infants [22]. BF infants had to be exclusively breastfed for at least 3 complete months, and formula-fed (FF) infants were randomized to one of the study formula milks before the age of 8 weeks.

\section{Data Collection}

Anthropometric data and data from standardized questionnaires were introduced at each study center and transferred into a central data base (RDE Software GmbH, Munich, Germany). At the age of 1-9 and 12 months, parents were asked to complete a 3 -day food protocol (including 2 weekdays and 1 weekend day). The dietary data were collected prospectively, and no attempts were made to modify parental decision making on introducing solids, liquids or potentially allergenic foods to the infant diet. The study personnel were explicitly advised to collect detailed information on dietary intake of the infants and to provide no recommendations on complementary feeding to the parents. The food protocol data were introduced into our own software by nutritionists at the different study centers and then transferred into a central data base. Standard operating procedures were developed to harmonize the calculation and introduction of food intake data.

At the beginning of the study, mothers and fathers were asked about their history of allergy and atopic diseases like a doctor's diagnosis of asthma, hay fever, allergy, atopic dermatitis or others.

\section{Allergenic Foods}

Complementary foods consumed during the first year of life by the infants of all 5 countries (3,281 food items) were classified by their ingredients. We defined as potentially allergenic complementary foods any foods containing gluten, milk, egg, fish, soy or 
Table 1. Number of infants and percentages by country of evaluated 3-day food protocols at the age of 4, 6, 9 and 12 months

\begin{tabular}{|c|c|c|c|c|c|c|c|c|c|c|}
\hline & \multicolumn{10}{|c|}{ Age, completed months } \\
\hline & \multicolumn{2}{|l|}{3} & \multicolumn{2}{|l|}{4} & \multicolumn{2}{|l|}{6} & \multicolumn{2}{|l|}{9} & \multicolumn{2}{|l|}{12} \\
\hline & $\mathrm{n}$ & $\%$ & $\mathrm{n}$ & $\%$ & $\mathrm{n}$ & $\%$ & $\mathrm{n}$ & $\%$ & $\mathrm{n}$ & $\%$ \\
\hline \multicolumn{11}{|l|}{ BF infants } \\
\hline Germany & 64 & 19 & 61 & 19 & 59 & 19 & 55 & 19 & 50 & 17 \\
\hline Belgium & 27 & 8 & 37 & 11 & 48 & 15 & 44 & 15 & 46 & 16 \\
\hline Italy & 126 & 38 & 116 & 35 & 109 & 34 & 98 & 35 & 101 & 35 \\
\hline Poland & 48 & 14 & 45 & 14 & 44 & 14 & 41 & 14 & 41 & 14 \\
\hline Spain & 71 & 21 & 70 & 21 & 57 & 18 & 46 & 16 & 48 & 17 \\
\hline Total & 336 & 100 & 329 & 100 & 317 & 100 & 284 & 100 & 286 & 100 \\
\hline \multicolumn{11}{|l|}{ FF infants } \\
\hline Germany & 139 & 16 & 131 & 16 & 125 & 17 & 109 & 16 & 101 & 15 \\
\hline Belgium & 95 & 11 & 90 & 11 & 80 & 11 & 74 & 11 & 67 & 10 \\
\hline Italy & 207 & 24 & 200 & 25 & 193 & 25 & 183 & 27 & 180 & 27 \\
\hline Poland & 162 & 19 & 154 & 19 & 146 & 19 & 129 & 19 & 132 & 20 \\
\hline Spain & 244 & 29 & 231 & 29 & 213 & 28 & 187 & 27 & 178 & 27 \\
\hline Total & 847 & 100 & 806 & 100 & 757 & 100 & 682 & 100 & 658 & 100 \\
\hline
\end{tabular}

nuts. For the evaluation of milk introduction, we included any milk or dairy product other than infant or follow-on formula. This included primarily cow's milk and products derived from cow's milk and, in a few cases, milk from goat, sheep or buffalo and their products.

We defined as soy product any food item containing soy (e.g. soy milk, soy yogurt, lecithin of soy, soybean oil) and as soy protein any food item containing soy protein (e.g. soy milk, soy formula, soy yogurt, tofu, dessert from soy milk).

\section{Sociodemographic Data}

We grouped mothers into 4 categories based on age at delivery: category I = age $\leq 25$ years; category II = age $>25$ to 30 years; cat egory III $=$ age $>30$ to 35 years, and category IV $=$ age $>35$ years Maternal educational levels were categorized in 3 groups: no/low education = pre-preliminary to lower secondary (no schooling to elementary education); middle education = upper secondary and post-secondary (high school), and high education = first and second stage of tertiary education (college, university or institutes of technology).

\section{Statistics}

To avoid cofounders, we decided to analyze BF and FF infants in separate groups. Mainly the $\chi^{2}$ test and logistic regression analysis were used to investigate differences in the introduction of potentially allergenic foods. Stata 9.2, SPSS 16.0, and Excel were used for data analyses.

\section{Ethics}

The study protocol was reviewed by the ethic committees of all study centers. Written informed parental consent was obtained for each infant.

Allergenic Foods in the Infant's Diet

\section{Results}

A total of 1,678 infants, $588 \mathrm{BF}$ and 1,090 FF infants, and their mothers/parents were recruited and their data analyzed. At least one 3-day food diary was available for evaluation in 1,368 (82\%) infants. At the age of 3 completed months, 1,183 three-day weighed food diaries could be evaluated, at 4 completed months 1,135, at 6 completed months 1,074, at 9 completed months 966, and at 12 completed months 944 (table 1). At the age of 2 and 3 months, we analyzed the food protocols from $95 \%$ $(1,127 / 1,184)$ of all infants in the study, from $77 \%$ $(983 / 1,275)$ between the age of 3 and 6 months, from $72 \%$ $(808 / 1,116)$ between 3 and 9 months, and from $70 \%$ $(756 / 1,085)$ up to 12 months of age.

Some sociodemographic characteristics of the study $\mathrm{BF}$ and FF infants are shown in online supplementary table 1 (for all supplementary material see www. karger.com/doi/10.1159/000326766).

\section{BF Infants}

In our study population, $92 \%$ of the $\mathrm{BF}$ infants were breastfed until the age of 20 weeks and $75 \%$ until the age of 28 weeks.

At the age of 4 completed months, we found some $6 \%$ of BF infants consuming at least one potentially allergenic food and $51 \%$ at the age of 6 completed months (fig. 1).

Ann Nutr Metab 2011;58:109-117 


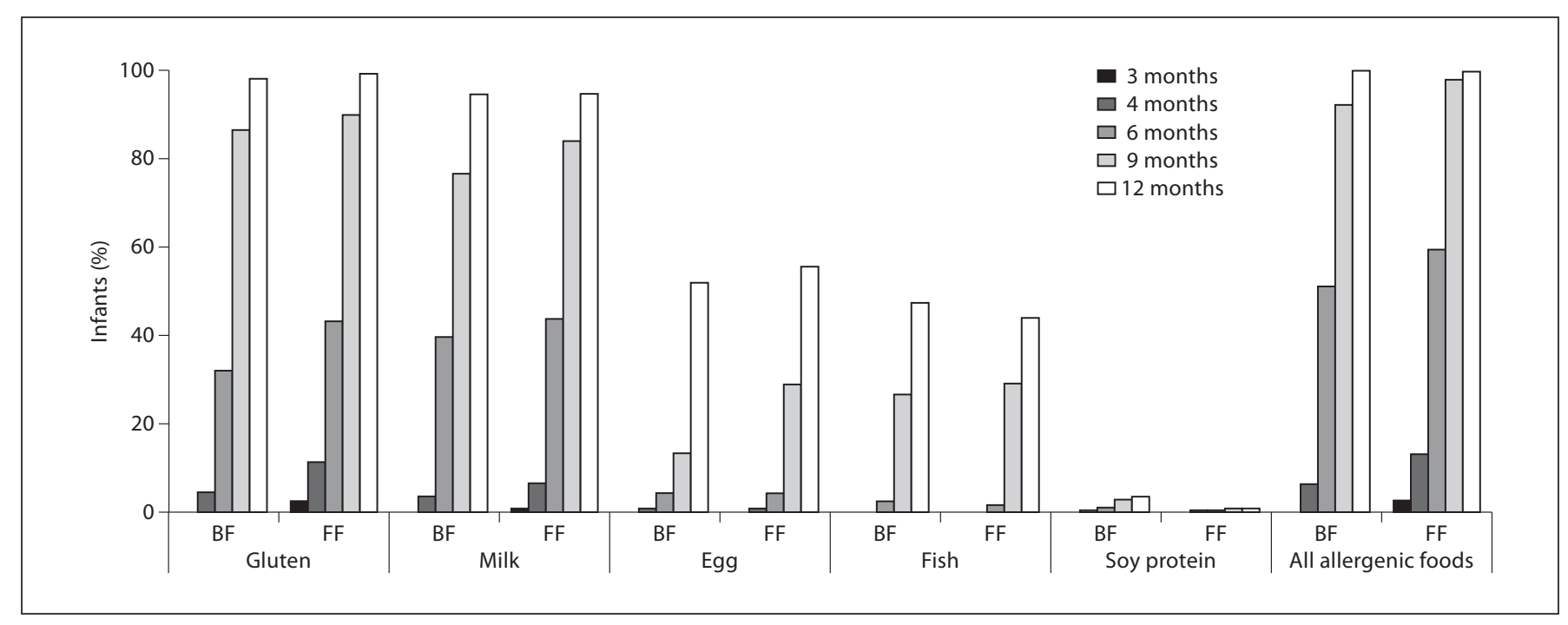

Fig. 1. Percentage of BF and FF infants with an intake of potentially allergenic foods during the first year. Allergenic foods include gluten, milk, egg, fish and soy protein.

The median for the introduction of potentially allergenic food was at the age of 28 weeks (95\% CI 27.3-28.7) for BF infants.

Data from the food protocols showed no BF infant with an intake of food with gluten at the age of 3 completed months, while $4 \%$ of BF infants received food with gluten at the age of 4 completed months and $32 \%$ at the age of 6 completed months (fig. 1).

We found significant differences between the countries in the proportions of BF infants with intake of food with gluten (at each month at the ages of 4-9 months; $p<0.001$; table 2). At the age of 4 completed months, $22 \%$ of the BF infants in Belgium, $6 \%$ in Spain and 2\% in Italy consumed some food with gluten. At the age of 6 completed months, we found the highest proportion of $\mathrm{BF}$ infants with an intake of food with gluten in Belgium (58\%) and the lowest in Poland (7\%) (table 2). After comparing several parameters of the parents of BF infants receiving gluten before the national recommended time point of introduction, we found the lowest proportion of $\mathrm{BF}$ infants receiving gluten by mothers with the lowest educational level $(\mathrm{p}<0.05)$.

At the age of 4 and 6 completed months, 3 and $39 \%$ of the BF infants, respectively, consumed some milk or food with milk or milk product other than breast milk or formula milk (fig. 1). We found significant differences in the percentages of infants with consumption of milk or milk products between the countries in each month at the age of $4-12$ months ( $p<0.01$; table 2$)$. At the ages of 4 and 5 completed months, we found the highest proportions of BF infants with an intake of milk or food with milk or milk product in Belgium (19 and 22\%, respectively; table 2). In the second half of the first year, Italy had the highest proportion of BF infants with milk or food with milk or milk product consumption (77-99\%). In contrast, we found the lowest proportions of infants with an intake of milk or food with milk or milk product at the age of 6-9 months in Poland (0-59\%) and in Germany (20$56 \%)$.

Some 1 and $4 \%$ of the BF infants consumed some egg or food with egg at the ages of 4 and 6 months, respectively (fig. 1). The time points for introduction of egg or food with egg were significantly different between the countries (at each month from 4 to 12 months; $\mathrm{p}<0.005$; table 2). At the age of 4 and 5 completed months, only infants in Belgium received some egg or food with egg (5 and 7\%, respectively) and at the age of 6 completed months they had the highest proportion of infants with consumption of egg or food with egg (21\%), while in the other countries, not more than $2 \%$ of all BF infants consumed some egg or food with egg. At the age of 7-12 completed months, Poland (30-76\%), Belgium (29-76\%) and Germany (10-62\%) had the highest proportions of infants with egg or food with egg intake, whereas in Italy and Spain no more than $10 \%$ of the BF infants had received some egg or food with egg by the age of 9 months.

No fish or food with fish was eaten until the age of 4 completed months, and only $2 \%$ of all BF infants received 
fish or food with fish at the age of 6 completed months (fig. 1). Separated by country, $6 \%$ in Belgium, $4 \%$ in Spain and $2 \%$ in Italy consumed some fish or food with fish at the age of 6 completed months (table 2). At the age of 7-12 completed months, Italy (17-71\%), Belgium (15-48\%) and Spain (4-73\%) had the highest proportions of infants with fish or food with fish intake. In Germany and Poland, no more than $10 \%$ of the infants consumed fish or food with fish during the first year of life.

Nuts or some food with nuts were consumed by $<4$ and $8 \%$ of the BF infants at the ages of 9 and 12 months, respectively. During the first year of life, we found the highest proportions of infants with nut or food with nut intake in Belgium (17\%) and Germany (14\%) and the lowest in Italy (3\%), Poland (5\%) and Spain (4\%).

Many infants in Belgium (up to 54\%) and Germany (up to $37 \%$ ) consumed soy products or food with soy during the first year of life, whereas in the other countries, no more than $5 \%$ of the BF infants consumed soy products or food with soy. However, not more than $4 \%$ of the BF infants consumed soy protein or food with soy protein (soy formula milk, soy milk dessert, ingredient of a dish) during the first year. There were very low proportions of infants with an intake of food with soy protein (fig. 1). In Italy, we found $1-3 \%$ of the BF infants with intake of food with soy protein from the age of 4-12 months, and we found the highest proportion in Belgium with up to $11 \%$ (table 2).

We found significant differences in sociodemographic characteristics (online suppl. table 1) between the study groups of each country in BF infants, but there was no association between intake of food with gluten, milk, egg and fish and maternal age at birth, educational level and smoking habit, nor with the infant's birth weight and birth order of the infants.

About $31 \%$ of the BF infants had a parent with a history of allergy and atopic diseases (18\% of the fathers, $16 \%$ of the mothers) at the beginning of the study. There were no significant differences in the proportions of mothers, fathers or both parents with a history of allergy and atopic diseases between the countries.

\section{FF Infants}

In our study cohort, 249 (23\%) infants were exclusively formula fed since birth, all others gradually switched from breastfeeding to formula feeding within the first 8 weeks of life. The median age was 14 days (interquartile range 3-30) at randomization and 16 days (interquartile range $2-29$ ) at the baseline visit.

Allergenic Foods in the Infant's Diet
Table 2. Percentage of BF infants with an intake of typical allergenic foods at the ages of 4, 6, 9 and 12 months

\begin{tabular}{|c|c|c|c|c|}
\hline \multicolumn{5}{|c|}{ Age, completed months } \\
\hline Gluten & $4^{\mathrm{a}}$ & $6^{\mathrm{a}}$ & $9^{b}$ & 12 \\
\hline Germany & - & 28.8 & 85.5 & 100.0 \\
\hline Belgium & 21.6 & 58.3 & 90.9 & 97.8 \\
\hline Italy & 1.7 & 34.9 & 94.9 & 100.0 \\
\hline Poland & - & 6.8 & 75.6 & 92.7 \\
\hline Spain & 5.7 & 26.3 & 76.1 & 97.9 \\
\hline Milk & $4^{\mathrm{b}}$ & $6^{\mathrm{a}}$ & $9^{a}$ & $12^{\mathrm{b}}$ \\
\hline Germany & - & 20.3 & 56.4 & 84.0 \\
\hline Belgium & 18.9 & 43.8 & 75.0 & 95.7 \\
\hline Italy & 1.7 & 77.1 & 96.9 & 99.0 \\
\hline Poland & - & - & 58.5 & 95.1 \\
\hline Spain & 2.9 & 14.0 & 73.9 & 93.8 \\
\hline$E g g$ & $4^{\mathrm{b}}$ & $6^{\mathrm{a}}$ & $9^{a}$ & $12^{\mathrm{a}}$ \\
\hline Germany & - & 1.7 & 18.2 & 62.0 \\
\hline Belgium & 5.4 & 20.8 & 43.2 & 76.1 \\
\hline Italy & - & 0.9 & 10.2 & 32.7 \\
\hline Poland & - & 2.3 & 53.7 & 75.6 \\
\hline Spain & - & - & 8.7 & 37.5 \\
\hline Fish & 4 & 6 & $9^{a}$ & $12^{\mathrm{a}}$ \\
\hline Germany & - & - & 1.8 & 10.0 \\
\hline Belgium & - & 6.3 & 25.0 & 47.8 \\
\hline Italy & - & 1.8 & 52.0 & 71.3 \\
\hline Poland & - & - & - & 2.4 \\
\hline Spain & - & 3.5 & 26.1 & 72.9 \\
\hline Soyprotein & 4 & 6 & 9 & $12^{\mathrm{c}}$ \\
\hline Germany & - & - & - & 2.0 \\
\hline Belgium & - & - & 6.8 & 10.9 \\
\hline Italy & 0.9 & 2.8 & 3.1 & 3.0 \\
\hline Poland & - & - & 4.9 & 2.4 \\
\hline Spain & - & - & - & - \\
\hline
\end{tabular}

Applying the $\chi^{2}$ test for each month of age, we found significant differences ( $\left.{ }^{\mathrm{a}} \mathrm{p}<0.001,{ }^{\mathrm{b}} \mathrm{p}<0.01,{ }^{\mathrm{c}} \mathrm{p}<0.05\right)$ in the proportions of BF infants with an intake of potentially allergenic foods like gluten, milk, egg, fish and soy protein, between the countries.

Some $13 \%$ of FF infants consumed at least one potentially allergenic food at the age of 4 completed months and $59 \%$ at the age of 6 completed months (fig. 1). The median for the introduction of potentially allergenic food was at the age of 26 weeks (95\% CI 25.2-26.2) for FF infants. It was significantly earlier compared to the BF infants $(\mathrm{p}<0.001)$.

We found $0.3 \% \mathrm{FF}$ infants with consumption of food with gluten at the age of 1 month, $0.8 \%$ at $2,2 \%$ at 3 and $11 \%$ at the age of 4 completed months. At the age of 6 completed months, $43 \%$ of the FF infants had consumed some food with gluten (fig. 1).

Ann Nutr Metab 2011:58:109-117 
Table 3. Percentage of FF infants with an intake of typical allergenic foods at the ages of 4, 6, 9 and 12 months

\begin{tabular}{|c|c|c|c|c|}
\hline \multicolumn{5}{|c|}{ Age, completed months } \\
\hline Gluten & $4^{\mathrm{a}}$ & $6^{\mathrm{a}}$ & $9^{\mathrm{a}}$ & 12 \\
\hline Germany & 13.7 & 69.6 & 97.2 & 99.0 \\
\hline Belgium & 24.4 & 51.3 & 97.3 & 98.5 \\
\hline Italy & 10.5 & 51.3 & 96.7 & 99.4 \\
\hline Poland & 5.2 & 26.7 & 81.4 & 98.5 \\
\hline Spain & 9.1 & 28.2 & 85.6 & 98.9 \\
\hline Milk & $4^{\mathrm{a}}$ & $6^{\mathrm{a}}$ & $9^{b}$ & $12^{\mathrm{a}}$ \\
\hline Germany & 11.5 & 58.4 & 92.7 & 96.0 \\
\hline Belgium & 14.4 & 31.3 & 79.7 & 91.0 \\
\hline Italy & 9.5 & 87.6 & 97.3 & 100.0 \\
\hline Poland & 0.6 & 15.8 & 72.1 & 93.2 \\
\hline Spain & 1.7 & 18.8 & 75.9 & 91.0 \\
\hline Egg & 4 & $6^{\mathrm{a}}$ & $9^{a}$ & $12^{\mathrm{a}}$ \\
\hline Germany & 2.3 & 8.0 & 32.1 & 73.3 \\
\hline Belgium & 1.1 & 7.5 & 59.5 & 64.2 \\
\hline Italy & 0.5 & 0.5 & 9.3 & 41.7 \\
\hline Poland & - & 9.6 & 65.9 & 90.2 \\
\hline Spain & - & - & 8.0 & 30.3 \\
\hline Fish & 4 & $6^{c}$ & $9^{\mathrm{a}}$ & $12^{\mathrm{a}}$ \\
\hline Germany & - & - & 5.5 & 8.9 \\
\hline Belgium & - & 3.8 & 40.5 & 49.3 \\
\hline Italy & - & 2.6 & 45.9 & 55.6 \\
\hline Poland & - & - & 2.3 & 11.4 \\
\hline Spain & - & 0.9 & 40.1 & 73.6 \\
\hline Soy protein & 4 & 6 & 9 & $12^{\mathrm{b}}$ \\
\hline Germany & - & - & 1.8 & 3.0 \\
\hline Belgium & 1.1 & 1.3 & 2.7 & 3.0 \\
\hline Italy & - & - & - & - \\
\hline Poland & - & - & - & - \\
\hline Spain & - & - & 0.5 & - \\
\hline
\end{tabular}

Applying the $\chi^{2}$ test for each month of age, we found significant differences $\left({ }^{\mathrm{a}} \mathrm{p}<0.001,{ }^{\mathrm{b}} \mathrm{p}<0.01,{ }^{\mathrm{c}} \mathrm{p}<0.05\right)$ in the proportions of FF infants with an intake of potentially allergenic foods like gluten, milk, egg, fish and soy protein, between the countries.

There were significant differences between countries in the proportions of FF infants with consumption of products containing gluten in each one of the first 9 months of life ( $<<0.001$; table 3). Belgium had the highest proportions of infants with an intake of food with gluten in the first 5 completed months of life (up to 38\%). At the age of 4 completed months in Belgium, Germany and Italy, more than $10-25 \%$ of FF infants had been fed some food with gluten. At 6 completed months, Germany (70\%) had the highest and Poland (27\%) and Spain (28\%) the lowest proportions of FF infants with food intake with gluten.
Milk or any food with milk or dairy product other than infant formula was consumed at the ages of 4 and 6 completed months by 7 and $44 \%$ of the FF infants, respectively (fig. 1). The proportions of FF infants with intake of milk, food with milk or dairy products were significantly different between the countries (in each month, $2-12$ months of age, $p<0.05$ ). At the age of $2-4$ completed months, Belgium had the highest proportions of infants with an intake of some milk other than formula milk (3-14\%; table 3). At the age of 5-12 completed months, Germany (39-96\%) and Italy (88-100\%) had the highest proportion of infants with consumption of milk, food with milk or dairy products intake, Poland (5-93\%) and Spain (7-91\%) the lowest. In Italy, more than $90 \%$ of the FF infants had received some milk or dairy products at the age of 7 completed months.

At the age of 5-8 months, we found significantly higher proportions of FF infants with milk, food with milk or dairy products intake with a low and middle maternal educational level compared to infants of mothers with a higher educational level $(\mathrm{p}<0.05)$.

Less than $1 \%$ of FF infants consumed some food with egg during the first 4 months of life, not more than $4 \%$ at the age of 6 completed months (fig. 1) and $<10 \%$ in each country (table 3 ). In the second half of the first year, we found the highest proportions of FF infants with an intake of egg or some food with egg in Poland (43-90\%), Belgium (8-64\%) and Germany (8-73\%), and the lowest in Italy (1-42\%) and Spain (0-30\%; table 3).

No infant consumed any fish or any food with fish until the age of 4 completed months and not more than $2 \%$ at the age of 6 completed months (fig. 1). Belgium (19$49 \%)$, Italy (17-56\%) and Spain (8-74\%) had the highest proportions of FF infants with fish or some food with fish intake during 7-12 months of age (table 3).

Nuts or some food with nuts were consumed by $<7 \%$ of all FF infants during the first year of life. The highest proportions of infants with nut intake or of some food with nuts were in Belgium (22\%; through Muesli, cookies, Nutella, pudding, syrup) and Germany (18\%; through cakes or cookies, Muesli, Nutella, pudding, bread) and $<3 \%$ in the other countries during the first year of life.

Some 2 and $6 \%$ of all FF infants consumed soy products or some food with soy products at the age of 4 and 6 completed months, respectively. At the age of 4 and 6 completed months, 1 and 10\% of FF infants in Germany consumed soy products or some food with soy products, and 12 and $43 \%$ in Belgium. In the other countries, there was no consumption of food with soy products during the first 6 months of life. 
Less than $1 \%$ of all FF infants consumed some food with soy protein (soy formula, tofu, dessert from soy milk) during the first year (fig. 1). FF infants receiving foods with soy protein during the first year of life were only found in Germany and Belgium (not more than 3\%; table 3).

We found significant differences in sociodemographic characteristics (online suppl. table 1) between the study groups of each country in FF infants but there were no associations between the intake of food with gluten, milk, egg and fish and birth weight, birth order or smoking habits of the mother.

About $21 \%$ of the FF infants had a parent with a history of allergy and atopic diseases (11\% of the fathers, $13 \%$ of the mothers). We found significant different proportions of mothers $(p<0.001)$ and fathers $(p=0.003)$ with a history of allergy and atopic diseases between the countries.

\section{Discussion}

In our study population of apparently healthy infants, FF infants received potentially allergenic foods like foods with gluten, milk and egg earlier than BF infants. In contrast, soy protein was introduced earlier and in higher proportion to BF infants, mainly due to the introduction of soy formula. There were large differences between countries for the introduction of potentially allergenic foods.

Although European and national recommendations advised not to introduce complementary foods before 4 months $[5,9]$ or even before 6 months of age [7], $6 \%$ of BF infants and $13 \%$ of FF infants had received potentially allergenic food (mainly foods with gluten and milk) at the age of 4 completed months. National recommendations at the time of our data collection advised to introduce foods with gluten not before 6 months and even from 8 months onwards in Spain and after the age of 9 months in Poland [24-27], congruent with the lowest proportion of $\mathrm{BF}$ and $\mathrm{FF}$ infants consuming gluten until the age of 9 months in these two countries.

Intake of foods containing gluten before the age of 3 months was associated with increased islet autoantibodies in infants [28]. The highest proportion of FF infants receiving foods with gluten was found in Belgium (10\%) due to the consumption of flour mixtures, cereals for infant porridge and cookies. Traditionally, there is a high consumption of antireflux infant formula in Belgium which may have led to more frequent use of cereals in the infant diet during the first months of life.

Allergenic Foods in the Infant's Diet
The intake of milk or dairy products as separate food items or as ingredients of foods other than breast milk or formula milk were highest in Belgian $\mathrm{BF}$ infants at the age of 4 and 5 completed months and in Belgian FF infants at the age of 2-4 completed months due to the consumption of milk-cereal meals, cookies, dairy products or as ingredient of meals. From the age of 6 completed months, we find the highest proportions of infants with consumption of some milk in Italy, probably due to the use of milk porridge and cheese (Grana, Parmigiano, Formaggino) added to the infant's meal. Some $76 \%$ of BF infants and $84 \%$ of FF infants of the total cohort consumed any milk other than infant formula at the age of 9 completed months and around 95\% at the age of 12 months. Thus, nearly all infants received cow's milk during the first year of life, mostly as part of a milk cereal meal, as milk product (yogurt, curd mixture or cheese) or as ingredient of a product or meal but not as drink. In most countries, the introduction of cow's milk as drink is recommended to be delayed until after 12 months of age [5].

The consumption of milk other than breast milk or infant or follow-on formula in apparently healthy infants, especially in FF infants consuming formula milk based on cow's milk, may be irrelevant with respect to the risk of atopy. Milk or dairy products were consumed at the ages of 4 and 6 completed months by 3 and $39 \%$ of BF infants and 6 and 44\% of FF infants, respectively.

Almost no food with egg, fish and soy protein was consumed during the first 6 months by $\mathrm{BF}$ and $\mathrm{FF}$ infants. Around $52 \%$ of BF infants and $56 \%$ of FF infants consumed some egg or food with egg and $48 \%$ of BF and $44 \%$ of FF infants consumed some fish or food with fish at the end of the first year of life. Indeed, we found significant differences between the countries in the proportions of $\mathrm{BF}$ and FF infants with some consumption of egg or fish during the second half of the year. The highest proportion of infants with fish intake was found in Italy, Belgium and Spain. This was in line with the national recommendations that suggested fish intake after 6 months in Belgium, not before 7-8 months in Italy, 9-10 months in Spain and not earlier than at the age of 2 years in Poland. When evaluating sociodemographic characteristics and the parental history of allergy and atopic diseases with regard to the time of potential allergenic food introduction in relation to the national recommendations of each country, separated by BF and FF infants, we found that the age of the mother, her educational level and the parental history of allergy and atopic diseases in some cases influenced the time point of introduction (data not

Ann Nutr Metab 2011;58:109-117 
shown). National eating habits and geographic distance of the study centers to the sea may further influence feeding practice.

The presence or absence of maternal allergy or atopic disease does not affect the consumption patterns of potentially allergenic foods during the first year of life (online suppl. table 2). When applying multiple regression analysis for $\mathrm{BF}$ and $\mathrm{FF}$ infants for each month at the ages of 3-6 months, including the effects of maternal or paternal history of allergy or atopic diseases, country of residence, maternal age, maternal education level and smoking behavior, the strongest and most consistent predictor was the country of residence.

For our dietary data collection, we have chosen 3-day weighed food protocols, one of the most reliable methods for capturing eating habits of children. One limitation of this method is that foods which are not eaten on a regular first months of life is relatively uniform, a 3-day food protocol is considered quite representative of infant eating habits. Also, there was a high percentage of infants with monthly food protocols (95\% in the first months and 70\% between 3 and 12 months of age).

In conclusion, this study documents an earlier introduction of potentially allergenic foods in FF infants than in $\mathrm{BF}$ infants as well as significant differences between countries for the time of introduction. Recent studies indicate that the introduction of complementary foods including potentially allergenic foods - between the age of 4 and 6 completed months was associated with a reduced risk of food allergy and atopic diseases, in some observations with stronger protective effects if the infant was still breastfed at the time of complementary food introduction [1, 15, 29-31]. These data support simplification of recommendations and practice of complementary feeding, with introduction of all suitable complementary foods in all infants not before 17 weeks and not later than 26 weeks of age [5].

\section{Appendix}

Study Team

Belgium (ULB Bruxelles and CHC St. Vincent Liège): C. Carlier, P. Goyens, J. Hoyos, J.-P. Langhendries, J.-N. Van Hees and A. Xhonneux.

Germany (Division of Pediatric Epidemiology, Institute of Social Pediatrics and Adolescent Medicine, and Division of $\mathrm{Nu}-$ tritional Medicine and Metabolism, Dr. von Hauner Children's Hospital, Ludwig Maximilian University of Munich): J. Beyer, H. Demmelmair, M. Fritsch, U. Handel, I. Hannibal, S. Kreichauf, R. von Kries, I. Pawellek and S. Verwied-Jorky. basis may not be captured. Since food intake during the

Italy (University of Milan): M. Giovannini, C. Agostoni, F. Confalonieri, S. Tedeschi, F. Vecchi and E. Verduci.

Spain (Universitat Rovira i Virgili): R. Closa Monasterolo, J. Escribano Subias and G. Méndez Riera.

Poland (Children's Memorial Health Institute): J. Socha, A. Dobrzańska, D. Gruszfeld, P. Socha, R. Janas, E. Pietraszek and A. Kowalik.

\section{Acknowledgements}

We are very grateful to the families participating in this study, for the efforts and time they have invested, as well as to the collaborating physicians, midwives and nurses for their helpful support in recruitment. We thank the whole study team for their effort, endurance and dedication to this work and for their help in informing and recruiting families. The European Childhood Obesity Project is being carried out with financial support of the European Community, under the 5th Framework Programme for Research, Technology and Demonstration 'Quality of Life and Management of Living Resources', Key Action 1 (Food, Nutrition and Health), contract number QLK1-CT2002-389, and the 6th Framework Priority 5.4.3.1 Food Quality and Safety (Early Nutrition Programming - long term follow-up of efficacy and safety trials and integrated epidemiological, genetic, animal, consumer and economic research, EARNEST, Food-CT-2005-007036). Berthold Koletzko is the recipient of a Freedom to Discover Award of the Bristol Myers Squibb Foundation, New York, N.Y., USA. The presented data are part of the PhD Thesis in Human Biology submitted by Sonia A. Schiess to the Medical Faculty of Ludwig Maximilian University of Munich.
References
1 Greer FR, Sicherer SH, Burks AW, and the Committee on Nutrition and Section on Allergy and Immunology: Effects of early nutritional interventions on the development of atopic disease in infants and children: the role of maternal dietary restriction, breastfeeding, timing of introduction of complementary foods, and hydrolyzed formulas. Pediatrics 2008;121:183-191.

2 Foote KD, Marriott LD: Weaning of infants. Arch Dis Child 2003;88:488-492.

3 Kajosaari M: Atopy prevention in childhood: the role of diet. Pediatr Allergy Immunol 1994;5(suppl):26-28.

4 Fergusson DM, Horwood LJ, Shannon FT: Early solid feeding and recurrent childhood eczema: a 10-year longitudinal study. Pediatrics 1990;86:541-546.

5 ESPGHAN Committee of Nutrition, Agostoni C, Decsi T, Fewtrell M, Goulet O, Kolacek S, Koletzko B, Fleischer Michaelsen K, Moreno L, Puntis JWL, Rigo J, Shamir R, Szajewska H, Turck D, van Goudoevere J: the ESPGHAN Committee on Nutrition. J Pediatr Gastroenterol Nutr 2008;46:99-110. Complementary feeding: a commentary by 
6 ESPGHAN Committee on Nutrition, Agostoni C, Braegger C, Decsi T, Kolacek S, Koletzko B, Michaelsen KF, Mihatsch W, Moreno L, Puntis J, Shamir R, Szajewska H, Turck D, von Guodoever J: Breast-feeding: a commentary by the ESPGHAN Committee on Nutrition. J Pediatr Gastroenterol Nutr 2009;49:112-125.

7 WHO 54th World Health Assembly: Infant and young child nutrition. WHA54.2. 2001. http://apps.who.int/gb/archive/pdf_files/ WHA54/ea54r2.pdf.

8 Koletzko B: Complementary foods and the development of food allergy. Pediatrics 2000; 106:1285.

9 Host A, Koletzko B, Dreborg S, Muraro A, Wahn U, Aggett P, Bresson JL, Hernell O, Lafeber H, Michaelsen KF, Micheli JL, Rigo J, Weaver L, Heymans H, Strobel S, Vandenplas Y: Dietary products used in infants for treatment and prevention of food allergy. Joint Statement of the European Society for Paediatric Allergology and Clinical Immunology (ESPACI) Committee on Hypoallergenic Formulas and the European Society for Paediatric Gastroenterology, Hepatology and Nutrition (ESPGHAN) Committee on Nutrition. Arch Dis Child 1999;81:80-84.

10 Saarinen UM, Kajosaari M: Breastfeeding as prophylaxis against atopic disease: prospective follow-up study until 17 years old. Lancet 1995;346:1065-1069.

11 Dutch State Institute for Nutrition and Health, Van Rossum CMT, Buechner FL, Hoechstra J: Quantification of health effects of breastfeeding. Review of the literature and model situation. Dutch State Institute for Nutrition and Health. RIVM Report 350040001/2005. 2005. http://www.rivm.nl/ bibliotheek/rapporten/350040001.pdf.

12 Agency for Healthcare Research and Quality: Breastfeeding and maternal and infant health outcomes in developed countries. AHRQ publication No 07-E007. 2007. http:// www.ncbi.nlm.nih.gov/books/bv.fcgi? rid=hstat1b.chapter.106732.

13 Oddy WH, Holt PG, Sly PD, Read AW, Landau LI, Stanley FJ, Kendall GE, Burton PR: Association between breast feeding and asthma in 6 year old children: findings of a prospective birth cohort study. BMJ 1999; 319:815-819.
14 Fiocchi A, Assa'ad A, Bahna S: Food allergy and the introduction of solid foods to infants: a consensus document. Ann Allergy Asthma Immunol 2006;97:10-21.

15 Muraro A, Dreborg S, Halken S, Høst A, Niggemann B, Aalberse R, Arshad SH, von Berg A, Carlsen KH, Eigenmann P, Hill D, Jones C, Mellon M, Oldeus G, Oranje A, Pacual C, Prescott S, Sampson H, Svartengren M, Vandenplas Y, Wahn U, Warner JA, Warner JO, Wickman M, Wickman M, Zeiger RS: Dietary prevention of allergic diseases in infants and small children. 3. Critical review of published peer-reviewed observational and interventional studies and final recommendations. Pediatr Allergy Immunol 2004; 15:291-307.

16 Zutavern A, Brockow I, Schaaf B, Bolte G, von Berg A, Diez U, Borte M, Herbarth O, Wichmann HE, Heinrich J, the LISA Study Group: Timing of solid food introduction in relation to atopic dermatitis and atopic sensitization: results from a prospective birth cohort study. Pediatrics 2006;117:401-411.

17 Zutavern A, Brockow I, Schaaf B, von Berg A, Diez U, Borte M, Kraemer U, Herbarth O, Behrendt H, Wichmann HE, Heinrich J, LISA Study Group: Timing of solid food introduction in relation to eczema, asthma, allergic rhinitis, and food and inhalant sensitization at the age of 6 years: results from the prospective birth cohort study LISA. Pediatrics 2008;121:e44-e52.

18 Filipiak B, Zutavern A, Koletzko S, von Berg A, Brockow I, Grübl A, Berdel D, Reinhardt D, Bauer CP, Wichmann HE, Heinrich J: Solid food introduction in relation to eczema: results from a four-year prospective birth cohort study. J Pediatr 2007;151:352-358

19 Snijders BEP, Thijs C, van Ree R, van den Brandt PA: Age at first introduction of cow milk products and other food products in relation to infant atopic manifestations in the first 2 years of life: the KOALA Birth Cohort Study. Pediatrics 2008;122:e115-e122.

20 Alm B, Aberg N, Erdes L, Mollborg P, Pettersson R, Norvenius SG, Goksor E, Wennergren G: Early introduction of fish decreases the risk of eczema in infants. Arch Dis Child 2009;94:11-15.
21 Kull I, Bergström A, Lilja G, Pershagen G, Wickman M: Fish consumption during the first year of life and development of allergic diseases during childhood. Allergy 2006;61: 1009-1015.

22 Koletzko B, von Kries R, Monasterolo RC, Subias JE, Scaglioni S, Giovannini M, Beyer J, Demmelmair H, Gruszfeld D, Dobrzanska A, Sengier A, Langhendries JP, Rolland Cachera MF, Grote V, for the European Childhood Obesity Trial Study Group: Lower protein in infant formula is associated with lower weight up to age 2 years: a randomized clinical trial. Am J Clin Nutr 2009; 89:1-10

23 Schiess S, Grote V, Scaglioni S, Luque V, Martin F, Stolarczyk A, Vechi F, Koletzko B: Introduction of complementary feeding in five European countries. J Pediatr Gastroenterol Nutr 2010;50:92-98.

24 O.N.E. Bon appétit les bébés! Fernand Gaubelle (Ed) O.N.E. Pamphlet 1998;20-39.

25 Savino F, Castagno E, Silvestro L: Lo Svezzamento: La Realtà Pratica. Milano, Pediatria, 2004.

26 Ksiazyk J, Rudzka-Kantoch Z, Weker H: Feeding plan for breast-fed infants and non-breast-fed infants. Medycyna Praktyczna Pediatria 2001;5:1-2.

27 Lázaro Almarza A: Diversificación alimentaria en pediatría. An Esp Pediatr 2001;54: 150-152.

28 Ziegler AG, Schmid S, Huber D, Hummel M, Bonifacio E: Early infant feeding and risk of developing type 1 diabetes-associated autoantibodies. JAMA 2003;290:1721-1728.

29 Ivarsson A, Hernell O, Stenlund H, Persson LA: Breast-feeding protects against celiac disease. Am J Clin Nutr 2002;75:914-921.

30 Akobeng AK, Ramanan AV, Buchan I, Heller RF: Effect of breast feeding on risk of celiac disease: a systematic review and meta-analysis of observational studies. Arch Dis Child 2006;91:39-43.

31 Norris JM, Barriga K, Hoffenberg EJ, Taki I, Miao D, Haas JE, Emery LM, Sokol RJ, Erlich HA, Eisenbarth GS, Rewers M: Risk of celiac disease autoimmunity and timing of gluten introduction in the diet of infants at increased risk of disease. JAMA 2005;293: 2343-2351. 